\title{
Recognition of medically compromised conditions in Pakistani Dental Treatment Seekers at Bahria University Dental Hospital: A Retrospective study.
}

\author{
Daud Mirza ${ }^{1}$, Anum Baqar ${ }^{2}$, Tahir $\mathrm{Ali}^{3}$, Saman Hakeem, Sehrish Ahmed ${ }^{5}$, Asim \\ Monpuri $^{6}$, Gazal Raza ${ }^{7}$, Moona Mumtaz ${ }^{8}$. \\ ${ }^{1}$ (Oral Pathology, Bahria University Medical and Dental college , Karachi, Pakistan) \\ ${ }^{2}$ (Prosthodontics, Bahria University Medical and Dental college, Karachi, Pakistan) \\ ${ }_{3}^{3}$ (Oral Maxillofacial Surgery, Humdard University Medical and Dental college, Karachi, Pakistan) \\ ${ }^{4}$ (Prosthodontics, Bahria U niversity Medical and Dental college, Karachi, Pakistan) \\ ${ }_{5}^{5}$ (Oral Biology, Bahria University Medical and Dental college, Karachi, Pakistan) \\ ${ }^{6}$ Prosthodontics, Bahria University Medical and Dental college, Karachi, Pakistan) \\ ${ }^{7}$ (Oral Pathology, Bahria University Medical and Dental college, Karachi, Pakistan) \\ ${ }^{8}$ (Periodontology, Bahria University Medical and Dental college, Karachi, Pakistan)
}

\begin{abstract}
Dental practitioners in Pakistan not only encounter patients with dental problems but most of them have systemic diseases as well. The purpose of this study was to investigate frequency of systemic problems in association with age and gender. A retrospective analysis was performed using medical histories of 2958 patients requesting dental treatment during the year March 2012 to March 2015. The information extracted included the following: demographic data (age and gender), presence or absence of systemic diseases. Descriptive and comparative analysis were done using SPSS Windows statistical software package version 17.0. Chi- square test was the choice of analysis to test the significance of the undertaken objectives. 1631 (55.13\%) males and 1327 (44.86\%) females' were documents. The age ranged from 10 to 80 years with mean age of $29.65+13.95$ years. Out of the total dental charts reviewed 2412 (81.8\%) patients had insignificant medical history whereas 548 (18.6\%) reported known medical problems. Hypertension 328 (11.0\%) was the most prevalent reported medical condition followed by diabetes mellitus 67 (2.26\%) and hepatitis 41(1.3\%). With regard to the age, hypertension and diabetes mellitus were more subjugate in the age group of 41-60 year while hepatitis showed its command in the community of aged 21-40 year $(p=0.000)$. However insignificant relationship observed between gender and systemic disorders $(p=0.614)$. It is the prime responsibility of the dentist to get more updated medical knowledge to provide safe dental treatment. Careful medical history of the patient is recommended before starting the dental procedure because some patients may harbor medically compromised condition. If ignored intentionally or unintentionally may cause serious consequences.
\end{abstract}

Keyword: Dentist, Diabetes mellitus, Hepatitis, Hypertension, Pakistan, Retrospective.

\section{Introduction}

Oral health care is an integral component of medical care. The negligence of oral hygiene may result in serious illness which may affect the quality of life of an individual [1]. In last few decades the technological advancement make the life easier, but simultaneously the people became away from physical exercise and balance dietary pattern therefore huge number of patients suffer from medical conditions, those may be the dental treatment seekers. Now this is the prime responsibility of the dentist, he/she should manage their patients effectively $[2,3]$. Patients with oral problems need to obtain a good medical history prior to any dental treatment. Moreover, dental management requires modifications in treatment procedures undertaking the relevant medical condition [5]. According to the National Centre for Health Statistics documented that $15 \%$ of adult population above 65 years of age may have chronic medical conditions. The most highly prevalent medical conditions are cardiovascular diseases, hypertension, diabetes, arthritis and chronic bronchitis [1,4]. Therefore, the effective evaluation of medical history is an unavoidable aspect of the rationale for these challenges.

Medically compromised patients require more comprehensive evaluation, which indeed require more knowledge of medicine and dentistry to provide good quality of dental treatment. Therefore, a prerequisite was felt to study the prevalence of medically compromised conditions seeking dental treatment in our study setting. 


\section{Methodology}

This survey was conducted by reviewing the dental records of OPD patients managed at Bahria Dental hospital, Karachi from March 2012 to March 2015. Only patients nursed by the faculty members in the department of Oral Medicine were included. The sample size comprises of 2960 patients, selected using convenience sampling technique. Demographic data regarding age and gender were recorded with the medical status. The medical status was categorized into 12 conditions as follows: medically fit or unknown disorder, hypertension, diabetes, asthma, tuberculosis, angina, hepatitis, thyroid disorders, renal disorders, skin disorders, arthritis and peptic ulcer. Descriptive analysis and comparison between the groups were performed using statistical package for social sciences version 17.0. Chi-square test was applied to obtain significant association between systemic disorders with age and gender respectively.

\section{Results}

A total of 2958 patient's record files were evaluated which comprises of 1631(55.13\%) males and $1327(44.86 \%)$ females' documents. The age ranged from 10 to 80 years with mean age of $29.65 \pm 13.95$ years. Out of the total dental charts reviewed $2410(81.4 \%)$ patients had insignificant medical history while 548 (18.6\%) reported known systemic disorders (fig 1). Hypertension $328(11.0 \%)$ was the most persistent medical condition followed by diabetes mellitus 67(2.2\%) and hepatitis 41(1.3\%) (fig 2)

With respect to the age, hypertension and diabetes mellitus were more dominate in the age group of 41 60 year while hepatitis showed its peak influence in the populace of aged 21-40 year. The association was highly significant. $(\mathrm{p}=0.000)$ (TABLE 1$)$

Further analysis of the results reveal that overall female gender $287(9.2 \%)$ was more affected than male one $261(8.5 \%)$. However, the statistical test showed insignificant relationship between medical disorders and gender. $(\mathrm{p}=0.614)$ (TABLE 2$)$

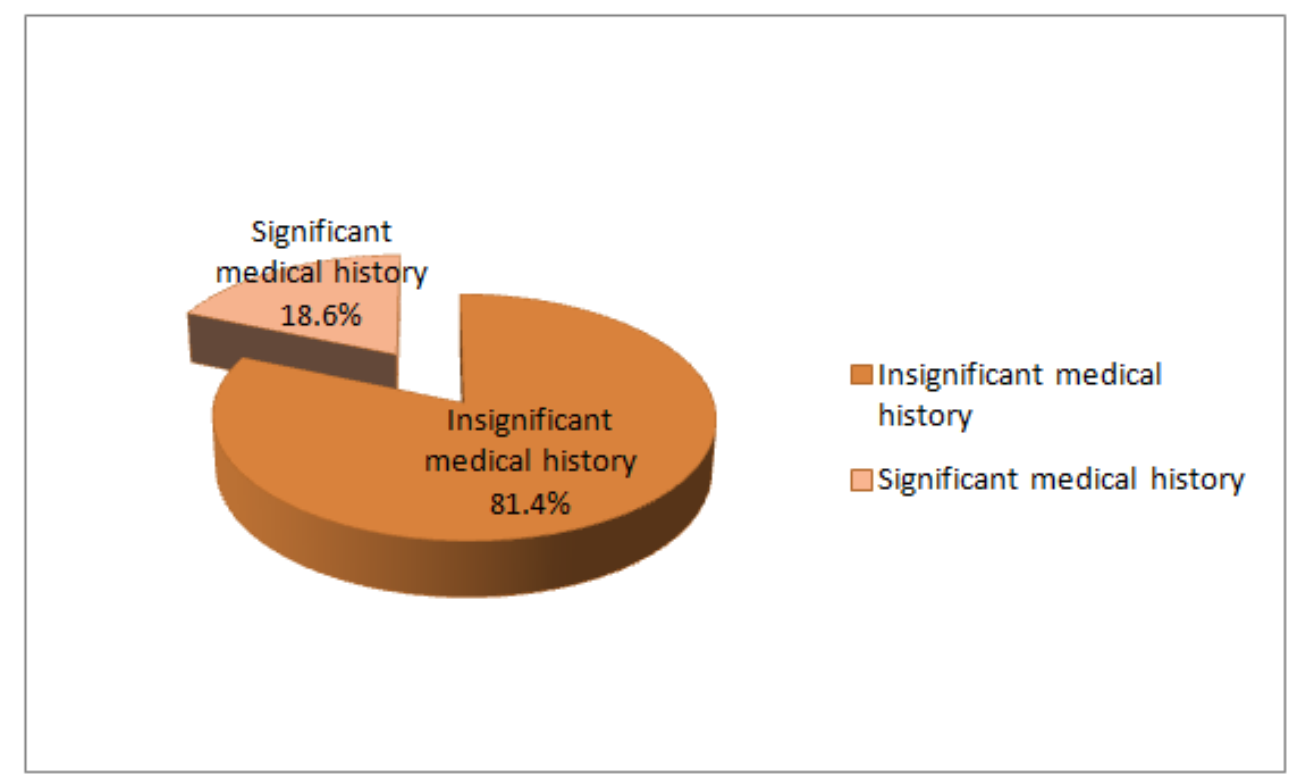

Fig 1: "percentage of significant and insignificant medical history in dental patients." 


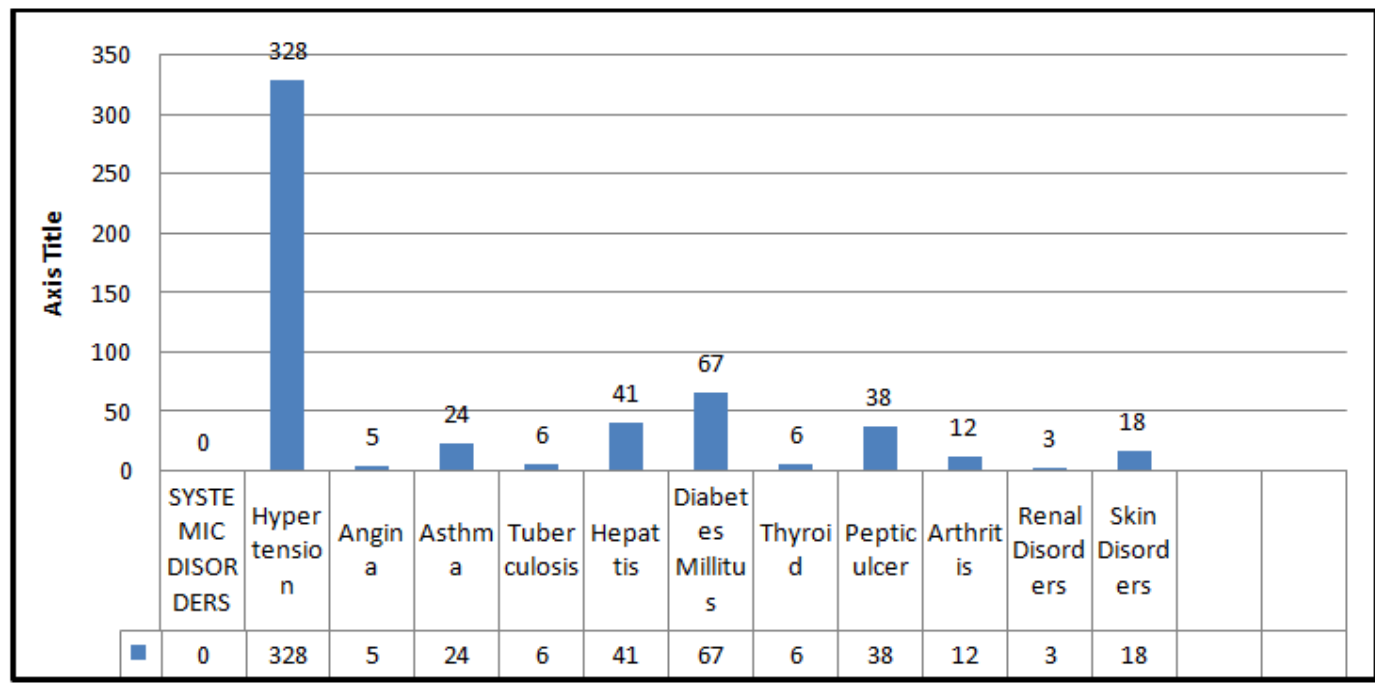

Fig 2: 'frequency of systemic disorders in dental treatment seekers

Table 1: 'frequency and percentage of medically compromised conditions in various age groups.'

\begin{tabular}{|c|c|c|c|c|c|c|c|c|c|c|c|}
\hline & \multirow{3}{*}{$\begin{array}{l}\text { SYSTEMIC } \\
\text { DISORDERS }\end{array}$} & \multicolumn{8}{|c|}{ Age group } & \multirow{2}{*}{\multicolumn{2}{|c|}{ Total }} \\
\hline & & \multicolumn{2}{|c|}{ below 20} & \multicolumn{2}{|c|}{$21-40$} & \multicolumn{2}{|c|}{$41-60$} & \multicolumn{2}{|c|}{ 61-80 } & & \\
\hline & & $\mathbf{n}$ & $\%$ & $\mathbf{n}$ & $\%$ & $\mathbf{n}$ & $\%$ & $\mathbf{N}$ & $\%$ & $\mathbf{n}$ & $\%$ \\
\hline 1 & Hypertension & 0 & 0.0 & 117 & 3.9 & 158 & 5.3 & 53 & 1.7 & 328 & 11.0 \\
\hline 2 & Angina & 0 & 0.0 & 3 & 0.1 & 2 & 0.0 & 0 & 0.0 & 5 & 0.1 \\
\hline 3 & Asthma & 4 & 0.1 & 16 & 0.5 & 3 & 0.1 & 1 & 0.0 & 24 & 0.8 \\
\hline 4 & Tuberculosis & 2 & 0.0 & 4 & 0.1 & 0 & 0.0 & 0 & 0.0 & 6 & 0.2 \\
\hline 5 & Hepattis & 6 & 0.2 & 23 & 0.7 & 11 & 0.3 & 1 & 0.0 & 41 & 1.3 \\
\hline 6 & Diabetes Millitus & 0 & 0.0 & 17 & 0.5 & 35 & 1.1 & 15 & 0.5 & 67 & 2.2 \\
\hline 7 & Thyriod & 1 & 0.0 & 3 & 0.1 & 2 & 0.0 & 0 & 0.0 & 6 & 0.2 \\
\hline 8 & Peptic ulcer & 2 & 0.0 & 19 & 0.6 & 15 & 0.5 & 2 & 0.0 & 38 & 1.2 \\
\hline 9 & Arthritis & 2 & 0.0 & 6 & 0.2 & 4 & 0.1 & 0 & 0.0 & 12 & 0.4 \\
\hline 10 & Renal disorders & 0 & 0.0 & 1 & 0.0 & 1 & 0.0 & 1 & 0.0 & 3 & 0.1 \\
\hline \multirow[t]{2}{*}{11} & Skin disorders & 5 & 0.1 & 13 & 0.4 & 0 & 0.0 & 0 & 0.0 & 18 & 0.6 \\
\hline & & 22 & 0.4 & 222 & 7.1 & 231 & 7.4 & 73 & 2.2 & 548 & 18.6 \\
\hline \multirow[t]{2}{*}{12} & Absent & 904 & 30.5 & 1190 & 40.2 & 288 & 9.7 & 28 & 0.9 & 2410 & 81.4 \\
\hline & TOTAL & 926 & 31.9 & 1412 & 47.3 & 519 & 17.1 & 101 & 3.1 & 2958 & 100.0 \\
\hline
\end{tabular}

Table 2: 'dissemination of gender wise systemic disturbances in terms of frequency and percentage.'

\begin{tabular}{|c|c|c|c|c|c|c|c|}
\hline \multirow{2}{*}{$\begin{array}{l}\text { SNo } \\
\cdot\end{array}$} & \multirow{2}{*}{$\begin{array}{l}\text { SYSTEMIC } \\
\text { DISORDERS }\end{array}$} & \multicolumn{2}{|l|}{ Male } & \multicolumn{2}{|c|}{ Female } & \multicolumn{2}{|l|}{ Total } \\
\hline & & $\mathbf{n}$ & $\%$ & $\mathbf{n}$ & $\%$ & $\mathbf{n}$ & $\%$ \\
\hline 1 & Hypertension & 142 & 4.8 & 186 & 6.2 & 328 & 11.0 \\
\hline 2 & Angina & 3 & 0.1 & 2 & 0.0 & 5 & 0.1 \\
\hline 3 & Asthma & 16 & 0.5 & 8 & 0.2 & 24 & 0.8 \\
\hline 4 & Tuberculosis & 3 & 0.1 & 3 & 0.1 & 6 & 0.2 \\
\hline 5 & Hepattis & 26 & 0.8 & 15 & 0.5 & 41 & 1.3 \\
\hline 6 & Diabetes Millitus & 33 & 1.1 & 34 & 1.1 & 67 & 2.2 \\
\hline 7 & Thyroid & 2 & 0.0 & 4 & 0.1 & 6 & 0.2 \\
\hline 8 & Peptic ulcer & 18 & 0.6 & 20 & 0.6 & 38 & 1.2 \\
\hline 9 & Arthritis & 5 & 0.1 & 7 & 0.2 & 12 & 0.4 \\
\hline 10 & Renal Disorders & 1 & 0.0 & 2 & 0.0 & 3 & 0.1 \\
\hline \multirow[t]{2}{*}{11} & Skin Disorders & 12 & 0.4 & 6 & 0.2 & 18 & 0.6 \\
\hline & & 261 & 8.5 & 287 & 9.2 & 548 & 18.6 \\
\hline \multirow[t]{2}{*}{12} & Absent & 1370 & 46.3 & 1040 & 35.1 & 2410 & 81.4 \\
\hline & Total & 1631 & 55.1 & 1327 & 44.8 & 2958 & 100.0 \\
\hline
\end{tabular}

\section{Discussion}

Medical health is consolidated with oral health care system. It is particularly valued when patient presents with medically comprised conditions that might alters or modifies the dental procedure. The rapidly growing population is forecasted to produce individuals with medical disorders that may affect oral health care 
system and its management. Thus dental clinician needs to understand the potential oral complications of dental therapy of medically compromised patients and their emergency care if needed followed by the conscious prescription of medications [6], [7].

To line up the above mentioned objectives, this paper deals to figure out the prevalence of systemic disorders in dental treatment seekers and to establish their relationship with age and gender.

The prevalence of medically compromised conditions in dental patients in the present study is $18.6 \%$. This figure is compatible when compared with the previous studies did by Ayanbadejo PO et al ,Dhanuthai K et al and Rhodus et al. [8,9,10]. They reported the occurrence of systemic conditions in dental patients in percentages of 22.1, 12.2 and 24.6 respectively. Varela MF et al in their investigation to rule out the prevalence of systemic diseases among patients requesting dental treatment in the public and private systems. They claimed $35.2 \%$ patients had some sort of systemic diseases compared to $28.1 \%$ patients in the private clinic. However certain studies have shown higher prevalence rates when compared to our result. Saengsirinavin et al discloses the prevalence of medical conditions to be $55.4 \%$ in Thai dental patients while Umino et al reported prevalence rate of medically compromised conditions was $64.2 \%$ in elderly Japanese dental patients [11], [12].

Cottone et al conducted survey on 4,365 patients and the result indicates that $68.5 \%$ patients had at least one significant medical issue [13]. Another study by Al-bayaty et al, 289 individuals were medically compromised and showed a prevalence rate of $42 \%$ [14]. This may be due to the fact that the present study employs patients having wide range of age in contrast to the most earlier mentioned studies which mainly focused on age group of elderly patients since the prevalence of medically compromised conditions tends to rise with age progression $[15,16]$.

The population residing in developing countries such as Pakistan does not undergo routine medical check-ups thus harboring asymptomatic medical conditions. It is also observed that patients with infectious or sexually transmitted diseases such as AIDS and hepatitis hide their past medical history undertaking the fear that there may be a delay or deny in their forehead dental procedures. As the present study is retrospective, the low figured out value may be attributed to the dentist disparity for not recording accurate medical history leads to unrevealed systemic disorders.

Oral disorders impart their effects on systemic health. According to Anitha and her colleagues demonstrated that the cardiovascular and periodontal diseases are directly related with each other [17]. Periodontal disease is also the 6th most usual consequence of diabetes mellitus [17]. Our analysis reveals hypertension is the preponderate disorder followed by diabetes milletus and hepatitis. Al-bayaty et al claims hypertension (12.6\%), diabetes mellitus (6.1\%) and asthma $(5.8 \%)$ are the most commonly encountered disorders, indulging 303 medical conditions (14). Almask K et al studied the medical records of 740 patients between Jan 2002 to June 2002. Their age range was 18-64 yrs. He found out that diabetes mellitus, hypertension, asthma and rheumatic heart disease were commonly observed disorders. This study is closely homogeneous to our investigation [18].

In contrast to ours, Cottone et al, surveyed 4,365 patients between 1975 and 1976 while cooperating 1833 medically compromised patients. He reported genito-urinary disease (19.8\%), allergy (19.2\%), respiratory disorders $(19.2 \%)$, gastrointestinal disorders $(17.9 \%)$, cardiovascular diseases $(15.8 \%)$, endocrine disorders $(8.3 \%)$, and musculoskeletal disorders $(15.1 \%)$ are the prevalent ones in dental treatment seekers [13]. Another investigation did by Anitha $\mathrm{V}$ et al in which approximately 92,177 patients' medical records were evaluated retrospectively from 2011- 2013 revealed $4.14 \%$ patients with medically compromised conditions. The percentages of the three most frequent systemic diseases encountered are cardiovascular disease (39.29\%), diabetes mellitus (35.45\%), and respiratory disorders (8.69\%) (17).

Pakistan is the sixth most populous country at Global population statistics, harboring around 191 million inhabitants with 16 million public residing in Karachi [6]. The prevalence of physical illness is alarmingly increasing in Pakistani population inspite of demographics being of lower BMI and nutrition. In males, the prevalence of hypertension increases from $<10 \%$ in age group of below 20 years to $>60 \%$ in age group of 70 years age. On the other hand in females it increases from $<5 \%$ in age group of below 20 years to a peak of $70 \%$ in 60 - 69 years of age, the prevalence being higher in the female compared to male [19]. In both males and females the prevalence rate increases steeply after 20 - 29 years age [19]. In addition, more than $70 \%$ of hypertensive patients are unaware of the disease $[19,20]$.

One of the representators of National Institute of Diabetes and Endocrinology of Pakistan, documented prevalence of diabetes around $7.6 \%$ in 2011 which will be increased by 2030. Pakistan will stand out at fourth in global ranking, owning 13.8 million diabetic community. More women than men die from diabetes annually [21]. According to senior consultant and Principal of Gujranwala Medical College, lack of primary and secondary health care facilities results in increased incidence of hepatitis in Pakistani population. It is at the peak on the world rating. Every 10th person is infected with it. Hepatitis takes away the lives of over 1.5 lakh sufferers every year [22]. 
The current study analysis also proclaims the significant relationship between systemic disorders and age. Generally higher prevalence is noted in the age group of 21-40 years. This is in accordance to Olojedo ACO et al study while Bhateja $S$ work contradicts to ours, reporting mean age of 50. 04 \pm 13.21 years $[1,23]$. However unremarkable association noted between prevalence of medical conditions and gender in the undertaken study. Male domination over female observed in Bhateja $\mathrm{S}$ investigation to figure out the prevalence rate of medically comprised a condition which is in contrast to our analysis. [1].

\section{Conclusion}

Hence the prevalence rate of known medical disorders is $18.6 \%$ in dental treatment seekers at Bahria University Dental Hospital, Karachi. Significant correspondence observed in relation to age group while no parallel connection noted between occurrence of systemic conditions and gender. The current investigation is retrospective in direction, conducted by reviewing the patient's record files. The considerable limitation is that it does not comprise the standard interview session and the clinical examination so patients with undiagnosed systemic conditions might be escaped in the present data.

\section{References}

[1]. S Bhateja, High prevalence of cardiovascular diseases among other medically compromised conditions in dental patients: A retrospective study, J Cardiovasc Dis Res, 3(2), 2012 Apr-Jun,113-116.

[2]. M. M Muñoz,Y.J Soriano, R.P Roda ,G Sarrión, Cardiovascular diseases in dental practice. Practical considerations, Med Oral Patol Oral Cir Bucal, 13,2008,296-302.

[3]. A.J Cerveró, J.V Bagán, Y.J Soriano,R.P Roda, Dental management in renal failure: Patients on dialysis, Med Oral Patol Oral Cir Bucal,13, 2008, 419-26.

[4]. E.R Pamuk, D.K Wagener,M.T Molla, Achieving na-tional health objectives: The impact on life expectancy and on healthy life expectancy, Am J Public Health, 94, 2004,378-83.

[5]. Dhanuthai K, K Sappayatosok , P Bijaphala , S Kulvitit , T Sereerat, Prevalence of medically compromised conditions in dental patients, Med Oral Patol Oral Cir Bucal, 14(6), 2009 287-91.

[6]. United Nations, Department of Economic and Social Affairs, Population Division (2015). World Population Prospects, The 2015 Revision.

[7]. K Ganda, Guidelines, Management of the medically compromised dental patient; part 1, 2006.

[8]. P.O Ayanbadejo, K.A Umeizudike, C.I Emeka ,G Alade ,K.O Savage,T.I Umeizudike, Self-Reported Medical Conditions and Oral Health Status of Patients seen in a Nigerian Dental Clinic, West Afr J Med,33(3), 2014 Jul-Sep,216-21.

[9]. K Dhanuthai, K Sappayatosok, P Bijaphala, S Kulvit ,T Sereerat, Prevalence of medically compromised conditions in dental patients, Med Oral Patol Oral Cir Bucal,14(6),2009 Jun,287-91.

[10]. N. L Rhodus ,M.B Bakdash, J.W Little, M.L Haider, Implications of the changing medical profile of a dental school patient population, J Am Dent Assoc,119,1989,414-6.

[11]. C Saengsirinavin, P Kraivaphan, P Phumara, Survey of drug used and medical history among dental out-patients, J Dent Assoc Thai, 40, 1990, 68-74

[12]. M Umino, M Nagao,Systemic diseases in elderly dental patients, Int Dent J,43, 1993, 213-8.

[13]. J.A Cottone, A.H Kafrawy, Medications and health histories: a survey of 4,365 dental patients, J Am Dent Assoc, 98, 1979, 713-8.

[14]. H.F Al-bayaty, P.R Murti, R.S Naidu, R Matthews, Medical problems among dental patients at the school of dentistry, the university of West Indies, Journal of Dental Education,73(12), 2009, 1408-14.

[15]. J.D Suomi, H.SHorowitz, J.P Barbano, Self-reported systemic conditions in an adult study population. J Dent Res. 1975;54:1092.

[16]. Galan D, Brecx M, Mayer L, Medical status, functional status and drug utilization patterns of a population of older dental patients in Winnipeg, Manitoba, J Can Dent Assoc, 63,1997,29-33.

[17]. V Anitha, V Shivakumar, P Rajesh, M Shanmugam, B Meenapriya, Amritha, G Priyadarshini, The Frequency of Medically Compromised Patients Visiting Chettinad Dental College and Research Institute : A Retrospective Study, Chettinad Health City Medical Journal, 2(4), 2013, 110 - 112

[18]. K Almas, F.A Awartani, Prevalence of medically compromised patients referred for periodontics treatment to teaching hospital in central Saudi Arabia, Saudi Med Journal, 24(11), 2003, 12-24-5.

[19]. National Health Survey, Islamabad: Pakistan Medical Research Council, 1998.

[20]. K Aziz ,S Aziz, N Patel, A.M Faruqui, H Chigani, Coronary heart disease risk factor profile in a lower middle class urban community in Pakistan, Eastern Mediterranean Health J, 11, 2005, 258-72 .

[21]. Z Shaikh,. The Express Tribune, 2011 May $5^{\text {th }}$

[22]. A Mohsin, The Nation newspaper, 2015 May $4^{\text {th }}$

[23]. A.C.O Olojede, W.L Adeyemo, O.M Gbotolorun, O Runsewe, S.A.B Oluseye, F.T Goncalves, The prevalence of medical conditions among patients attending oral and maxillofacial clinic at a secondary and a tertiary health institution in Lagos, Nigeria, Am. J. Med. Dent. Sci,1(1), 2013, 1-4 